\title{
Yale climate-change institute launched
}

Rajendra Pachauri, chairman of the Intergovernmental Panel on Climate Change (IPCC), will head a new climate and

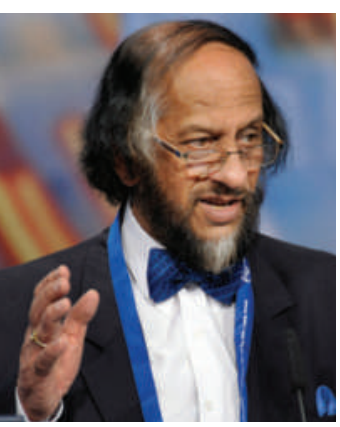

Rajendra Pachauri. Rajendra time at the Yale institute, retaining his current positions with the IPCC and as director-general of India's Energy and Resources Institute in New Delhi.

\section{NIH research to become permanently open access}

The annually renewable public-access policy first implemented by the US National Institutes of Health $(\mathrm{NIH})$ a year ago was made permanent in a spending bill signed into law on 11 March. The provision specifies that all NIH-funded investigators must submit an electronic version of their peer-reviewed manuscripts to the National Library of Medicine's PubMed Central. The manuscripts must be made publicly available no later than 12 months after publication.

The new law specifies that it must be implemented in a manner consistent with copyright law. Congressman John Conyers (Democrat, Michigan) is hoping to use that clause to upend the policy. His Fair Copyright in Research Works Act would amend US copyright law to forbid federal agencies from making funding agreements, such as $\mathrm{NIH}$ grants, conditional on authors making copies of their peer-reviewed articles freely available.

\section{Maths mistake blamed for killing off 'clean coal' plant}

The huge cost overruns cited as a reason for cancelling the US government's flagship carbon-sequestration plant, FutureGen,

\section{SOUNDBITES FROM COPENHAGEN}

Views from the International Scientific Congress on Climate Change, 10-12 March.

"On any kind of pragmatic timescale, I think we should see loss of the Amazon forest as irreversible."

Chris Jones Met Office Hadley Centre, Exeter, UK

“ I'm frustrated, as are many of my colleagues, that 30 years after the US National Academy of Sciences issued a strong warning on $\mathrm{CO}_{2}$ warming, the full urgency of this problem hasn't dawned on politicians and the general public."

Stefan Rahmstorf Potsdam Institute for Climate Impact Research, Germany
"Ice loss in Greenland has accelerated
over the last decade. The upper range of
sea level rise by $\mathbf{2 1 0 0}$ might be 1 metre
or more."
Konrad Steffen University of Colorado, Boulder
"Do the politicians understand just how
difficult it could be, just how devastating
$\mathbf{4 , 5 , 6}$ degrees centigrade would be? I
think, not yet."
Nicholas Stern former UK government economics
adviser

For coverage of the conference, see http://tinyurl. com/dm9plg and http://tinyurl.com/daroma 
were due in part to a mathematical error, a congressional report has found.

Announced by President George W. Bush in 2003, the plant was to have captured and stored $90 \%$ of its carbon dioxide emissions. It was originally slated to cost $\$ 950$ million, but was cancelled in early 2008 when new estimates pegged its cost at $\$ 1.8$ billion (see Nature 451, 612-613; 2008).

But those estimates were not comparable, the Government Accountability Office report says. The \$950-million estimate was done in constant dollars; the \$1.8-billion figure included expected increases for inflation. The 2008 figure would have been $\$ 1.3$ billion if adjusted for constant dollars.

Steven Chu, the new energy secretary, said last week that he plans to meet soon with private partners involved in the project to discuss whether and how to take it forward.

\section{Lighter Higgs boson harder to find}

Physicists have placed fresh limits on the mass of the Higgs boson - the particle thought to confer mass on other matter.

The particle was assumed to have an energy (or equivalent mass) of between 114 and 185 gigaelectronvolts $(\mathrm{GeV})$. But, after analysing pooled data, researchers

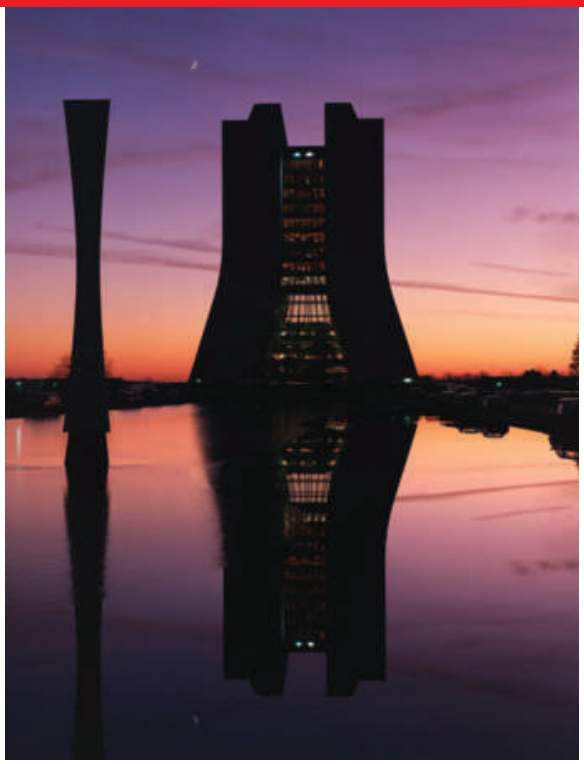

Fermilab's finding may cause problems for CERN.

at the Tevatron particle accelerator at the Fermi National Accelerator Laboratory in Batavia, Illinois, announced on 13 March that the particle can be excluded at energies of between 160 and $170 \mathrm{GeV}$, and is likely to exist at the lower end of the assumed range.

At more-crowded lower energies, filtering out other debris and finding a rare Higgs event becomes more difficult. Scientists at the Large Hadron Collider at CERN, Europe's particle-physics laboratory near
Geneva, had hoped to find the Higgs boson in the higher-energy region.

For a longer version of this story, see http://tinyurl.com/cp8avk.

\section{Hospital investigation reveals long-running fraud}

In what could be one of the largest ever cases of medical-research fraud, a prominent anaesthesiologist has been accused of fabricating data in at least 21 papers over 13 years.

Scott Reuben fabricated all or some of the data in studies as far back as 1996, according to an internal investigation by Baystate Medical Center in Springfield, Massachusetts, where he worked. Journals such as Anesthesiology and Anesthesia and Analgesia have already retracted Reuben's papers, which supported combining painkillers called COX-2 inhibitors (such as Merck's Vioxx and Pfizer's Celebrex) with other analgesics, including Pfizer's Lyrica, to relieve pain after surgery.

An attorney representing Reuben said that the Baystate investigation was confidential, that there were extenuating circumstances and that Reuben deeply regrets all that has happened. Reuben is barred from research at Baystate for at least a decade. 